\title{
Management of chronic or intermittent primary angle-closure glaucoma: a long-term follow-up of the results of peripheral iridectomy used as an initial procedure
}

\author{
T. JUSTIN PLAYFAIR AND PETER G. WATSON \\ From the Department of Ophthalmology, Addenbrooke's Hospital, Cambridge
}

SUMMARY Patients presenting with either intermittent closed-angle glaucoma which gave rise to subacute congestive attacks or with chronic angle-closure glaucoma were followed up over 12 years. Peripheral iridectomy was performed as a primary procedure on these patients during this period. It was found to be a highly effective procedure in those patients without field loss at the time of presentation, but because of the figures presented here we would recommend that any patient presenting with angle closure and disc and field changes should have a trabeculectomy performed as a primary procedure. We found no way of predicting which patients would require further surgery from the history, initial intraocular pressure, or the gonioscopic findings. No patient in this series developed malignant glaucoma after trabeculectomy although it occurred in 2 eyes after peripheral iridectomy.

The management of acute closed-angle glaucoma in which the intraocular pressure rises rapidly causing corneal oedema, pain, and vomiting is not in dispute; nor is the management of the fellow eye of a patient who has had an acute attack. Peripheral iridectomy is effective. When, however, the angle of the anterior chamber is found to be closed or partially so and the intraocular pressure raised only moderately or even not at all, the management becomes more difficult and controversial (Murphy and Spaeth, 1974).

Since the introduction of gonioscopy (Barkan, 1936) it has been assumed that those patients who have closed or very shallow angles would develop angle-closure attacks. It was also assumed the raised intraocular pressure was due to the iris occluding the angle if this could be shown to be in contact or largely so when the patient first attended (Chandler, 1952). Peripheral iridectomy should therefore be the treatment of choice. This approach largely ignores the fact that if an angle has been occluded for a prolonged period secondary changes occur in the drainage mechanisms (Barkan, 1954). However, it has been shown that chronic angle-closure glaucoma may result from the closure of the filtration angle by irido-corneal contact alone (Foulds and

Address for reprints: Mr P. G. Watson, FRCS, 17 Adams Road, Cambridge CB3 9AD
Table 1 Sex and age distribution

53 females with age range $43-82$ years and $66 \%$ between 61 and 80 years

31 males with age range $39-83$ years and $64 \cdot 5 \%$ between 61 and 80 years

Phillips, 1957), and it has been our custom (although not universally carried out) to treat this group of patients by peripheral iridectomy as a first procedure.

There is some evidence also that the administration of miotics to these eyes will precipitate an acute attack (Lowe, 1962; Chandler and Grant, 1962) so that rather than treat a patient with raised intraocular pressure and a closed angle with miotics they have been treated by peripheral iridectomy.

\section{Materials and methods}

Control was considered to have been achieved if the intraocular pressure was $21 \mathrm{mmHg}$ or less, there was a stable field with 2 and 5/2000 white targets on a Bjerrum screen, and the optic disc cupping did not change.

Eighty-four patients (168 eyes) were followed up from January 1965 until December 1976. There were 53 females and 31 males. The minimum followup was 4 months. The population is stable and white (Table 1). 
(a) Intraocular pressure control

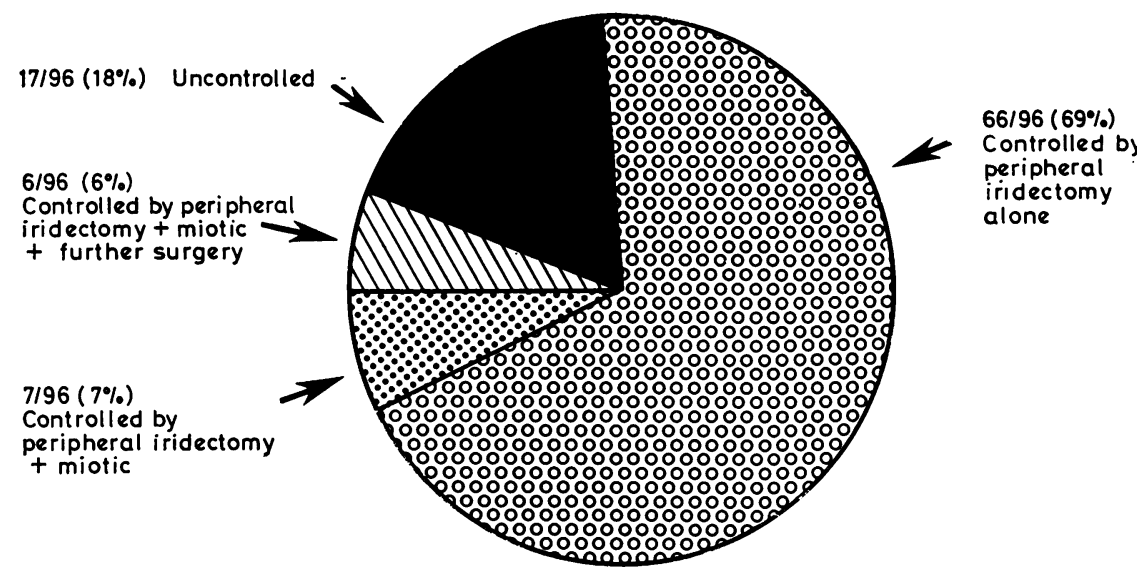

(b) Field control

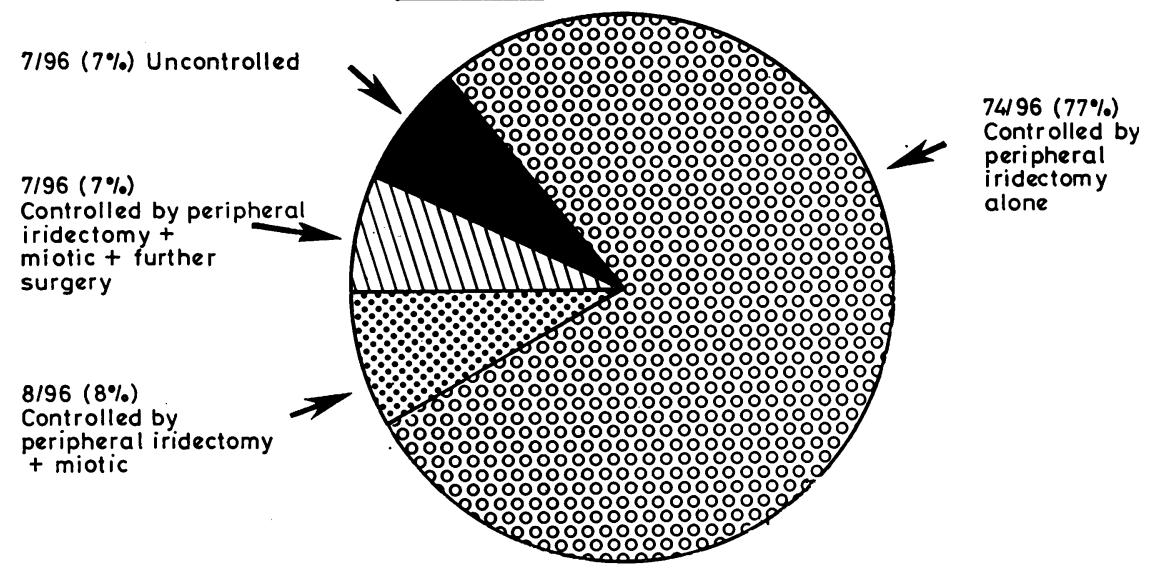

Figs. 1a,b Control of the glaucoma as judged by intraocular pressure control (a) and by the visual field (b) in patients who had no field loss at the time of presentation
One hundred and sixty eyes had initial operations during this period. Peripheral iridectomy was performed on 158 eyes and trabeculectomy on 2 eyes. Eight eyes were not operated upon for the reasons shown in Table 3 even though they fulfilled the criteria for surgery (Tables 2 and 3 ).

\section{Results}

The results of the various forms of therapy were analysed. The eyes were separated into 2 groups: those without field loss at presentation and those with field loss, and the degree of intraocular pressure and field control was compared (Figs. $1 a, b$, and $2 a, b)$. The intraocular pressure was controlled by peripheral iridectomy alone in $69 \%$ of those without field loss initially. In this group $77 \%$ had no further loss of field, while only $21 \%$ of those with field loss
Table 2 Type of operation performed

Number of eyes with peripheral iridectomy as initial procedure 158 Number of eyes with trabeculectomy as initial procedure

Number of eyes not operated on during this study

Table 3 Reasons for not operating in 8 eyes

6 eyes with absolute glaucoma and no perception of light ( 1 eye enucleated)

2 eyes with absolute glaucoma and prior anterior sclerectomy

1 eye prior to enucleation for glaucoma

when first seen had their intraocular pressure controlled or did not suffer further field loss when treated by peripheral iridectomy alone. At any one time $7 \%$ of those without field loss initially were 
(a) Intraocular pressure control

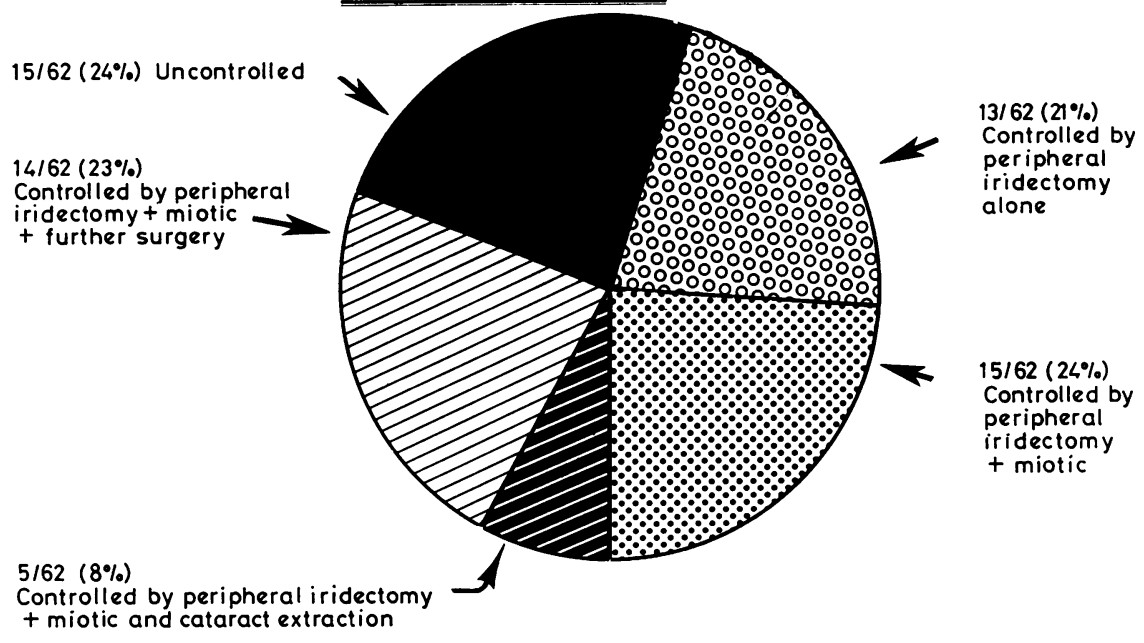

Figs. 2a, b Control of the glaucoma as judged by intraocular pressure control (a) and the visual field (b) in patients who showed field loss when they first presented$$
+ \text { miotic and cataract extraction }
$$

(b) Field control

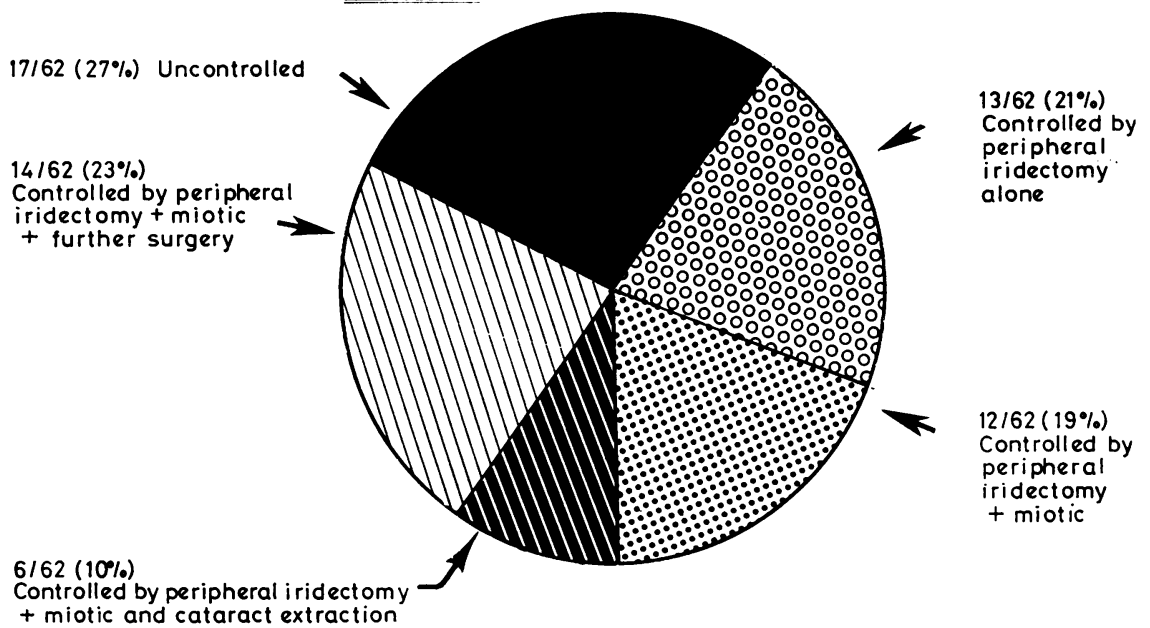

losing field, but $27 \%$ of those eyes with initial field loss were still losing field.

The results were further analysed to compare the degree of tension and field control with the findings on initial gonioscopy in those eyes without a history of congestive attacks (Table 4). The results were also

Table 4 Tension and field control versus gonioscopic assessment of angle (129 eyes)

\begin{tabular}{lrr}
\hline Gonioscopy findings & Tension control & Field control \\
\hline Narrow & $28 / 44(64 \%)$ & $30 / 44(68 \%)$ \\
$1-50 \%$ closure & $9 / 19(47 \%)$ & $10 / 19(53 \%)$ \\
$51-99 \%$ closure & $5 / 22(23 \%)$ & $6 / 22(27 \%)$ \\
$100 \%$ closure & $14 / 44(32 \%)$ & $15 / 44(34 \%)$ \\
\hline
\end{tabular}

Table 5 Eventual control of glaucoma when compared with an initial history of congestive attacks

\begin{tabular}{ll}
\hline Number of eyes with history of congestive episodes & 29 \\
Without initial field loss & 27 \\
Control of tension by peripheral iridectomy alone & $19 / 27$ \\
Control of field by peripheral iridectomy alone & $25 / 27$ \\
With initial field loss & 2 \\
Control of tension by peripheral iridectomy alone & $1 / 2$ \\
Control of field by peripheral iridectomy alone & $1 / 2$ \\
\hline
\end{tabular}

analysed from those patients who had had symptoms of congestive attacks (Table 5).

Of the 62 eyes with initial field loss and managed by peripheral iridectomy as an initial procedure 31 
had $100 \%$ closure of the angle at initial gonioscopy. The therapy and degree of tension and field control is seen in Tables 6 and 7.

Further surgery in this series was either trabeculectomy or Krasnov's iridocycloretraction. Further surgery has been carried out after initial peripheral iridectomy in 26 eyes (Table 8). Fifteen of the further surgical operations were performed on eyes with initial field loss and 50 to $100 \%$ closure of the angle on gonioscopy. Control had still not been achieved for intraocular pressure and/or field despite further surgery and miotics in 13 eyes out of 158 eyes treated initially by peripheral iridectomy. Cataract extraction was necessary in 17 of the 158 eyes $(11 \%)$ which had had peripheral iridectomies as primary procedures (Table 9).

\section{Discussion}

The patients in this study represented a heterogeneous group of glaucomas. They ranged from chronic simple glaucoma with narrow angles to classical primary chronic closed-angle glaucoma. If the

Table 6 Thirty-one eyes with 100\% closure of anterior chamber angle on gonioscopy and a field defect at first examination and the degree of control of tension and field with therapy

\begin{tabular}{|c|c|c|c|c|}
\hline \multirow{2}{*}{$\frac{\text { Treatment }}{\text { Peripheral iridectomy }}$} & \multicolumn{2}{|c|}{ Control of tension } & \multicolumn{2}{|c|}{ Control of field } \\
\hline & $6 / 31$ & $(19 \%)$ & $6 / 31$ & $(19 \%)$ \\
\hline $\begin{array}{l}\text { Peripheral iridectomy } \\
\quad+\text { miotic }\end{array}$ & $5 / 31$ & $(16 \%)$ & $4 / 31$ & $(13 \%)$ \\
\hline $\begin{array}{l}\text { Peripheral iridectomy } \\
\quad+\text { cataract extraction }\end{array}$ & $1 / 31$ & $(3 \%)$ & $2 / 21$ & $(10 \%)$ \\
\hline $\begin{array}{l}\text { Peripheral iridectomy } \\
\quad+\text { miotic } \\
\quad \text { + further operation }\end{array}$ & $7 / 31$ & $(23 \%)$ & $7 / 31$ & $(23 \%)$ \\
\hline $\begin{array}{l}\text { Uncontrolled at any } \\
\text { given time }\end{array}$ & $12 / 31$ & $(39 \%)$ & $12 / 31$ & $(39 \%)$ \\
\hline
\end{tabular}

Table 7 Fourteen eyes with $100 \%$ closure of anterior chamber angle on gonioscopy but without a field defect at first examination and the degree of control of tension and field with therapy

\begin{tabular}{|c|c|c|c|c|}
\hline \multirow{2}{*}{$\frac{\text { Treatment }}{\text { Peripheral iridectomy }}$} & \multicolumn{2}{|c|}{ Control of tension } & \multicolumn{2}{|c|}{ Control of field } \\
\hline & $8 / 14$ & $(57 \%)$ & $9 / 14$ & $(64 \%)$ \\
\hline $\begin{array}{l}\text { Peripheral iridectomy } \\
\quad+\text { miotic }\end{array}$ & $1 / 14$ & $(7 \%)$ & $3 / 14$ & $(21 \%)$ \\
\hline $\begin{array}{l}\text { Peripheral iridectomy } \\
\text { + cataract extraction }\end{array}$ & - & & - & \\
\hline $\begin{array}{l}\text { Peripheral iridectomy } \\
\quad+\text { miotic } \\
\quad \text { + further surgery }\end{array}$ & $1 / 14$ & $(7 \%)$ & $1 / 14$ & $(7 \%)$ \\
\hline $\begin{array}{l}\text { Uncontrolled at any } \\
\text { given time }\end{array}$ & $4 / 14$ & $(29 \%)$ & $1 / 14$ & $(7 \%)$ \\
\hline
\end{tabular}

Table 8 Further surgical procedures following peripheral iridectomy

\begin{tabular}{lcc}
\hline Krasnov's iridocycloretraction & 5 eyes & \\
Trabeculectomy & 24 eyes & \\
Procedure & Control of tension & Control of field \\
Krasnov's & $2 / 5$ & $2 / 5$ \\
Trabeculectomy & $18 / 24 \quad(75 \%)$ & $19 / 24 \quad(79 \%)$ \\
The three failed Krasnov operations were followed by trabeculectomy
\end{tabular}

Table 9 Cataract extractions (17 eyes)

\begin{tabular}{lll}
\hline & $\begin{array}{l}\text { Number of } \\
\text { extractions after } \\
\text { peripheral iridectomy } \\
\text { with or without } \\
\text { miotic }\end{array}$ & $\begin{array}{l}\text { Number of } \\
\text { extractions after } \\
\text { further surgery }\end{array}$ \\
\hline $\begin{array}{l}\text { Without initial field defect } \\
\text { (96 eyes) }\end{array}$ & $5(29 \%)$ & - \\
$\begin{array}{l}\text { With initial field defect } \\
\text { (62 eyes) }\end{array}$ & $10(59 \%)$ & $2 \quad(12 \%)$ \\
\hline
\end{tabular}

diagnosis of glaucoma requires the triad of raised intraocular pressure, cupped disc, and field defect, then many patients did not have glaucoma. Be that as it may, we are faced continually with the clinical decision of what is the best management for patients with variable combinations of intraocular pressure greater than $21 \mathrm{mmHg}$ and narrow through to $100 \%$ closed angles, with and without field defects.

It is generally accepted that peripheral iridectomies should be performed bilaterally if there has been a congestive attack or a history suggestive of that. Provided a careful check is made on the visual fields in the immediate postoperative period this is an entirely satisfactory procedure (Playfair and Watson, 1978). Repeated attacks of angle closure will probably cause peripheral anterior synechiae or trabecular damage and therefore make the glaucoma difficult to control. However, in this series the field was stabilised in 26 out of the 29 eyes by peripheral iridectomy alone. A history of congestive attacks was not found to be of any prognostic significance with regard to the need for further surgery.

We agree with Gelber and Anderson (1976) that the gonioscopic appearance of the angle is of little help in deciding when to perform a trabeculectomy as an initial procedure (Table 4). However, control was twice as likely if the angle was completely open as if it was completely closed. Many authors feel that there is a strong case for basing surgical decisions in closed-angle glaucoma on the degree of closure of the angle by peripheral anterior synechiae (Chandler, 1952; Shaffer, 1957; Forbes, 1974).

In those patients (and they are the majority) who have narrow to closed angles, minimal rises of 
tension or none at all, and who do not have field defects at the time of presentation the management is controversial. Although we might have managed these patients conservatively, we considered that peripheral iridectomy prevented further closure of the angle and damaging pressure rises (Tables 6 and 7) (Foulds and Phillips, 1957). Peripheral iridectomy will also permit the safe use of miotics if these become necessary.

The difficult patients are those who present initially with a field defect, cupped disc, variable angle closure, and raised intraocular pressure. Until now we have tended to manage these patients by performing peripheral iridectomies immediately and if control was ineffectual adding miotics, leaving further surgery until later. Peripheral iridectomy will certainly control classical chronic closed-angle glaucoma, but we have found this to be the diagnosis in only a minority of patients.

\section{CASE REPORTS}

A women was aged 71 in January 1975 when she was referred by her optician with glaucoma. She had had an amblyopic left eye (astigmatic) from childhood but had no complaints other than difficulty with reading. Her brother and sister had had glaucoma. Her visual acuities were right 6/18 (with 0.5DS), left 6/60 (not improved with spectacles). The intraocular tensions were right and left 60 $\mathrm{mmHg}$, the anterior chambers were shallow, and gonioscopy showed both angles to be $100 \%$ closed. The optic discs were grossly cupped. Bjerrum field testing showed bilateral gross arcuate scotomas. Acetazolamide $250 \mathrm{mg} 3$ times a day orally and pilocarpine $4 \% 3$ times a day to both eyes reduced the tensions to right $22 \mathrm{mmHg}$, left $15 \mathrm{mmHg}$, and opened both angles by 5 days. Bilateral peripheral iridectomies were performed. The intraocular pressures were thereafter controlled readily with pilocarpine $2 \% 3$ times a day. Unfortunately further surgery was frequently required (Table 8).

A woman was aged 65 in April 1974 when she went for a routine check for reading glasses. She was asymptomatic. Visual acuities were right $6 / 36$ (plano) and left 6/7.5 (+0.75 DS). The intraocular tensions were found to be right $62 \mathrm{mmHg}$, left $60 \mathrm{mmHg}$, and the optic discs to be severely cupped. Field examination on a Bjerrum screen showed there to be a gross right glaucomatous defect preserving a central island and variable arcuate scotoma in the left eye. On Goldmann gonioscopy the right angle was $100 \%$ closed and the left $75 \%$ closed. Bilateral peripheral iridectomies were performed that week. In August 1974, despite pilocarpine $4 \% 3$ times a day and acetazolamide $250 \mathrm{mg} 4$ times a day the intraocular tensions were right $36 \mathrm{mmHg}$, left $42 \mathrm{mmHg}$.
The angles were now open. There was a suggestion of further field loss, so bilateral trabeculectomies were performed.

The intraocular pressure remained controlled until July 1976 with pilocarpine $4 \%$ eye drops 3 times a day in both eyes. By then there was increasing nuclear sclerosis and the left field defect was larger, so bilateral Krasnov iridocycloretractions were performed. Over the next 9 months there was only tenuous control with pilocarpine eye drops, and in May 1977 both cataracts were removed through corneal sections. In September 1977 the intraocular tensions were right and left $25 \mathrm{mmHg}$, visual acuities with aphakic correction right $6 / 12$, left $6 / 9$, and the fields showed some improvement after the cataract extractions. Further pilocarpine therapy has not been necessary.

It was hoped that Krasnov's iridocycloretraction operation (Krasnov, 1969, 1971) would be the operation of choice in this situation, but unfortunately it has not proved to be. The operation has the theoretical advantage of opening the pathway to the trabeculum, but this may already be damaged. This possibility was recognised by Krasnov himself. Also it is said to be a non-drainage procedure and hence there would be less chance of malignant glaucoma developing. However, subconjunctival drainage was noted in some of our iridocycloretractions.

Malignant glaucoma followed peripheral iridectomy in each eye of 1 male patient. He was aged 54 when first seen in May 1966 with a 5-year history of abnormal vision in the left eye and a more recent left upper field defect. Visual acuity was right $6 / 6$, left $6 / 5$. The intraocular pressures were right $20 \mathrm{mmHg}$, left $27 \mathrm{mmHg}$. Gonioscopy showed $90 \%$ of the left angle and $40 \%$ of the right to be closed. The left disc was atrophic. The presence of a dense left-side arcuate scotoma was confirmed.

After initial therapy to the left eye with pilocarpine and acetazolamide a peripheral iridectomy was performed in June. The iris spontaneously prolapsed and the anterior chamber was not lost. On the fifth postoperative day the anterior chamber was absent and the tension $45 \mathrm{mmHg}$. The tension was controlled over several days with cyclopentolate $1 \%$ and oral glycerol. A further attack of malignant glaucoma occurred in August which could not be controlled medically, so a left intracapsular cataract extraction with broad iridectomy was performed. The anterior vitreous was removed at the same time.

In December 1966 a right peripheral iridectomy was performed. Six weeks later the patient presented with headache, haloes, and a flat right anterior chamber with a tension of $47 \mathrm{mmHg}$. This responded to $2 \%$ atropine drops. 
By June 1967 the tension in the left eye remained in the 30s despite medical therapy, and a left cyclodialysis was performed. This controlled the intraocular pressure. The left visual acuity with a contact lens was $6 / 18$, and a left squint operation was performed for secondary divergence in October 1971.

The glaucoma remained stable for the following 3 years. In November 1974, however, the patient complained of fluctuating vision in his right eye associated with haloes and pain. The tension in this right eye remained in the 30 s despite hyoscine drops $0.25 \%$ twice daily and acetazolamide. In March 1975 a right Krasnov iridocycloretraction was performed. In April 1975 he had a further episode of malignant glaucoma in this right eye which was controlled by hyoscine $0.25 \%$.

In July 1977 the visual acuity was right 6/12, left $6 / 9$, tensions $11 \mathrm{mmHg}$ right and left, and fields unchanged over the years on hyoscine $0.25 \%$ eye drops to the right eye in the morning and pilocarpine eye drops $1 \%$ twice daily to the left eye.

This patient followed a course similar to patients described by Chandler and Grant (Chandler, 1950; Chandler and Grant, 1962).

We have performed 26 trabeculectomies by the method described either by Cairns (1968) or by Watson (1972). There have been no cases of malignant glaucoma in patients treated this way. This is similar to the experience of Gelber and Anderson (1976). Nevertheless, the fear of this complication has often delayed the decision to do further surgery. Recently we have performed trabeculectomy much more readily after an initial peripheral iridectomy if control of the glaucoma was not complete. We now feel, as do Gelber and Anderson, that trabeculectomy is the operation of choice in patients presenting with classical chronic closed-angle glaucoma even though miotics and further trabeculectomy may be needed.

\section{Conclusions}

The eyes of patients with chronic angle-closure glaucoma often present with severe damage, and aggressive therapy is indicated. It is a sobering observation (Tables 6 and 7) that, if there was $100 \%$ closure of the angle, raised tension, and a field defect when the patient first presents, $38 \%$ will remain uncontrolled after peripheral iridectomy. We now feel that almost all these patients should have had trabeculectomies initially, but unfortunately we still do not know for certain who will not be adequately treated by peripheral iridectomy. There does not seem, however, to be any disadvantage in performing trabeculectomy rather than peripheral iridectomy in patients with raised intraocular pressure and field and disc changes, and we would now advocate its use as the initial procedure. Moreover, any patient who has had peripheral iridectomy needs to be closely watched after surgery, because although control may eventually be achieved it may take several months, during which time further severe field loss may occur.

We thank all the staff of the Eye Department for their help and co-operation in the collation of this material and in particular Mr J. E. Cairns and Mr J. D. Scott for their permission to include their patients in the survey. We would also like to thank Mrs J. McCombie for typing the manuscript and the Medical Illustration Department for its help with the tables.

\section{References}

Barkan, O. (1936). Recent advances in the surgery of chronic glaucoma. Transactions of the American Academy of Ophthalmology and Otolaryngology, 41, 469-488.

Barkan, O. (1954). Iridectomy in narrow-angle glaucoma. American Journal of Ophthalmology, 37, 504-519.

Cairns, J. E. (1968). Trabeculectomy: preliminary report of a new method. American Journal of Ophthalmology, 66, 673-679.

Chandler, P. G. (1950). Malignant glaucoma. Transactions of American Ophthalmological Society, 48, 128-143.

Chandler, P. A. (1952). Narrow-angle glaucoma. Archives of Ophthalmology, 47, 695-716.

Chandler, P. A., and Grant, W. M. (1962). Mydriaticcycloplegic treatment in malignant glaucoma. Archives of Ophthalmology, 68, 353-359.

Forbes, M. (1974). Indentation gonioscopy and efficacy of iridectomy in angle-closure glaucoma. Transactions of the American Ophthalmological Society, 72, 488-515.

Foulds, W. S., and Phillips, C. I. (1957). Some observations on chronic closed-angle glaucoma. British Journal of Ophthalmology, 41, 208-213.

Gelber, E. C., and Anderson, D. R. (1976). Surgical decisions in chronic angle closure glaucoma. Archives of Ophthalmology, 94, 1481-1484.

Krasnov, M. M. (1969). Microsurgery of glaucoma. Indications and choice of techniques. American Journal of Ophthalmology, 67, 857-864.

Krasnov, M. M. (1971). Iridocycloretraction in narrow-angle glaucoma. British Journal of Ophthalmology, 55, 389-395.

Lowe, R. F. (1962). Acute angle-closure glaucoma. The second eye: an analysis of 200 cases. British Journal of Ophthalmology, 46, 641-650.

Lowe, R. F. (1964). Primary creeping angle-closure glaucoma. British Journal of Ophthalmology, 48, 544-550.

Murphy, M. B., and Spaeth, G. L. (1974). Iridectomy in primary angle-closure glaucoma. Classification and differential diagnosis of glaucoma associated with narrowness of the angle. Archives of Ophthalmology, 91, 114-222.

Playfair, T. J., and Watson, P. G. (1979). Management of acute primary angle-closure glaucoma. A long-term follow-up of the results of peripheral iridectomy used as an initial procedure. British Journal of Ophthalmology, 63, 17-22.

Shaffer, R. N. (1957). Operating room gonioscopy in angle closure glaucoma surgery. Transactions of the American Ophthalmological Society, 55, 59-66.

Watson, P. G. (1972). Surgery of the glaucomas. British Journal of Ophthalmology, 56, 229-306. 